\title{
Zeolite MFI adsorbent for recovery of butanol from ABE fermentation broths produced from an inexpensive black liquor-derived hydrolyzate
}

\author{
Abrar Faisal $^{1,2} \cdot$ Ming Zhou $^{1} \cdot$ Jonas Hedlund ${ }^{1} \cdot$ Mattias Grahn ${ }^{1}$ (D) \\ Received: 14 March 2018 / Revised: 30 April 2018 / Accepted: 3 May 2018 /Published online: 11 May 2018 \\ (C) The Author(s) 2018
}

\begin{abstract}
In this work, high-silica MFI zeolite adsorbent was evaluated for selective recovery of butanol from a real ABE (acetone, butanol, and ethanol) fermentation broth by batch adsorption measurements. The fermentation broth was produced using a hydrolyzate originating from Kraft black liquor, an internal stream in pulp mills, i.e., a low-cost substrate. The adsorbent was very selective towards butanol and butyric acid and became nearly saturated with a mixture of butanol and butyric acid with relative amounts of butanol and butyric acid depending on the $\mathrm{pH}$. The presence of phenolic compounds in significant amounts in the fermentation broths, originating from the black liquor hydrolyzate, did not affect the adsorption of butanol and butyric acid.
\end{abstract}

Keywords ABE $\cdot$ Black liquor $\cdot$ Butanol $\cdot$ MFI $\cdot$ Butyric acid

\section{Introduction}

Black liquor is generated in pulp mills and mainly contains pulping chemicals, lignin, and degraded hemicellulose. It is currently combusted in a recovery boiler to recover the cooking chemicals and produce steam for electricity production and meeting heating needs in the plant. Large quantities of hemicellulose are lost in the cooking process to the black liquor stream (see [1] and references therein), and as the heating value of hemicellulose is not very high, extraction and use of this component as an inexpensive raw material for production of green fuels and chemicals, e.g., by fermentation, is an interesting option that may increase the profitability of the mills [2]. It has been shown that it is possible to separate the lignin and hemicellulose from the black liquor, e.g., by precipitating the lignin and use the hemicellulose for biochemical conversion into biofuels and chemicals [3]. In

Electronic supplementary material The online version of this article (https://doi.org/10.1007/s13399-018-0315-9) contains supplementary material, which is available to authorized users.

Mattias Grahn

mattias.grahn@1tu.se

1 Chemical Technology, Luleå University of Technology, SE 971 87 Luleå, Sweden

2 Present address: Department of Chemical Engineering, COMSATS Institute of Information Technology, Lahore 54000, Pakistan addition, removing lignin from the black liquor will reduce the thermal load on the recovery boiler, which is often the bottleneck for increased pulp production [4].

Recently, there has been a great interest to produce butanol via $\mathrm{ABE}$ fermentation using, e.g., the Clostridium acetobutylicum microorganism [5]. Biobutanol may for instance be used as a green gasoline substitute because of its favorable fuel properties [6, 7]. ABE fermentation yields acetone, butanol, and ethanol in the relative composition of ca. 3:6:1 respectively [8]. In addition to acetone, ethanol, and butanol, other components like butyric acid and acetic acid are also present in the fermentation broth. In ABE fermentation, sugars are first converted to acetic acid and butyric acid accompanied by the decrease in culture $\mathrm{pH}$ value in an acidogenic stage. In a second solventogenic phase, sugars and some of the acids are converted to acetone, butanol, and ethanol [9]. Kudahettige-Nilsson et al. showed in a recent study that it is possible to run an $\mathrm{ABE}$ fermentation using a hydrolyzate obtained from a black liquor precipitate [10]. Further, Mesfun et al. presented a techno-economic assessment for the production of biofuels from black liquor. They showed that with appropriate ABE (acetone, ethanol, and butanol) fermentation yield, biofuel production from this process could be economically feasible for pulping mills [11]. However, a key challenge for making this process feasible is to develop efficient technologies for recovering butanol from the dilute broth. Butanol is slightly toxic to the microorganisms, and therefore, the maximum concentration of butanol in 
the broth is limited to only $20 \mathrm{~g} / \mathrm{L}[7,12]$. Furthermore, butanol's higher boiling point compared to water and the presence of azeotropes sets further limits on suitable recovery options. To be able to commercialize this process, it is imperative to find an efficient downstream recovery method. Adsorption has been identified as an energy-efficient separation technique for the recovery of butanol as compared to pervaporation, distillation, gas-stripping, liquid-liquid extraction, and freeze crystallization $[13,14]$. In particular, adsorption on hydrophobic adsorbents has been identified as a promising technique for recovering butanol as shown in several recent investigations using both model solutions and real fermentation broths. Hydrophobic adsorbents like high-silica zeolites (including, e.g., the MFI, FER, CHA, and LTA frameworks), activated carbon, and metal organic frameworks, e.g., ZIF-8, have been evaluated for selective recovery of butanol. These adsorbents in general show good selectivities and capacities [15-22]. For example, Abdehagh et al. recently showed that biobutanol can be recovered using F-400 activated carbon from ABE model solutions [15]. Other groups studied recovery of butanol from model ABE solutions using KA-1 and polymeric resins with good outcome [23, 24]. However, most of these studies focused on recovery of butanol and other valuable compounds like butyric acid, etc. from model solutions and very little attention was given to recovery from real fermentation broths. Most studies have been performed on adsorption from liquid phase; however, recently, it was shown that high silica MFI zeolite showed very high butanol selectivity from vapor phase as reported by our group previously [25,26]. As zeolite MFI is a stable material and strightforward to synthesize in its hydrophobic (high $\mathrm{Si} / \mathrm{Al}$ ratio) form at relatively low cost, it is one of the most studied materials for recovering butanol from dilute aqueous solutions. Another key challenge for commercialization of the ABE process is the ability to yield high productivity and selectivity starting from inexpensive raw materials. In this respect, the carbohydrates, mainly in the form of hemicellulose, found in the black liquor constitute such an inexpensive source of substrate for the microorganisms. However, recovering butanol from fermentation broths prepared using the hemicellulose fraction from black liquor is an altogether different challenge. Kudahettige-Nilsson et al. recently demonstrated the possibility of utilizing hemicellulose from black liquor as substrate for ABE fermentation [10]. The hydrolyzate was prepared by using a precipitate of Kraft black liquor from a birch pulping line. Noticeably, the hydrolyzate contained phenols in significant amounts $(0.75 \mathrm{~g} / \mathrm{L})$. Presence of phenols in the fermentation broth may of course adversely affect the recovery of butanol from the fermentation broth. The composition of black liquor is quite complex, and typically, many different phenolic compounds are present; therefore, only the total phenolic content (TPC) is usually reported [10, 27, 28]. However, in a previous study, Löwendahl et al. showed that some of the phenolic compounds present in degraded lignin hydrolyzate are pcoumaric acid, ferulic acid, and syringic acid [29]. The presence of these compounds could potentially affect the adsorption of butanol and butyric acid in hydrophobic adsorbents. Therefore, it is important to identify suitable adsorbents with negligible effects of the phenols on the recovery of butanol from $\mathrm{ABE}$ fermentation broths. Many activated carbons are highly selective towards phenols when present in aqueous solutions; thus, this group of adsorbents would not be the first option [30-32]. On the other hand, the well-defined pore size of high-silica MFI zeolite (ca $5.5 \AA$ ) may be expected to exclude the typical phenolic compounds found in black liquor by molecular sieving. After adsorption, the products may be recovered from the adsorbent by, e.g., thermal desorption, to recover products and the zeolite can be thereafter be reused $[19,20,33]$. In this work, we therefore for the first time present data on the recovery of butanol and butyric acid from real $\mathrm{ABE}$ fermentation broths prepared from a black liquor hydrolyzate using a high-silica MFI zeolite adsorbent.

\section{Materials and method}

\subsection{Materials}

Commercial high-silica MFI zeolite powder from AkzoNobel, Sweden, with a $\mathrm{SiO}_{2} / \mathrm{Al}_{2} \mathrm{O}_{3}$ ratio of 230 was used as adsorbent in this study. In addition, binder-free high-silica MFI zeolite beads (G-360) from ACS materials, USA, with a $\mathrm{SiO}_{2} / \mathrm{Al}_{2} \mathrm{O}_{3}$ ratio of 360 were also used. Sodium hydroxide $(99.9 \%$, Merck chemicals) was used for adjusting the $\mathrm{pH}$ of the fermentation broth prior to the adsorption experiments when desired. The fermentation broth was prepared in house with details described elsewhere [10]. In brief, a precipitate of Kraft black liquor from a birch pulping line was supplied as filter cake (50-60\% dryness) from the Smurfit Kappa Kraftliner mill, in Piteå, Sweden. The precipitate was obtained by sparging carbon dioxide through the black liquor, thus decreasing the $\mathrm{pH}$ from ca 12.1 to 7.8 , which in turn promotes precipitation of the lignin. The precipitate contained approximately $15 \mathrm{wt} \%$ (dry weight) of xylan; the hemicellulose of interest and other components were mainly acetic acid, phenols (acid soluble lignin), solid lignin, and ash. The filter cake was hydrolyzed by adding $2 \mathrm{M}$ sulfuric acid to reach $\mathrm{pH}<1$, and kept at $121{ }^{\circ} \mathrm{C}$ for $60 \mathrm{~min}$. The xylose content in the hydrolyzate was $20-40 \mathrm{~g} / \mathrm{L}$. Batch ABE fermentation of the hydrolyzate using the Clostridium acetobutylicum ATCC 824 strain was conducted at $37{ }^{\circ} \mathrm{C}$ in an agitated 1-L bioreactor. The $\mathrm{pH}$ was controlled to 5.1 using automatic addition of an aqueous ammonium solution during 10 days of cultivation [10]. In addition, butanol (99\%) and ethanol (99\%) were purchased from Sigma Chemicals, Sweden. Acetone (99\%) was purchased from Merck Chemicals, Sweden. 


\subsection{Experimental methods}

Scanning electron microscopy (SEM) images were recorded on a FEI Magellan 400 field emission instrument without coating the samples. X-ray diffraction (XRD) data were recorded using a Panalytical Empyrean diffractometer run in Bragg-Brentano geometry, whereas nitrogen adsorption-desorption data were recorded at $77 \mathrm{~K}$ on an ASAP 2020 instrument from Micromeritics. Prior to measurements, the samples were outgassed at $350{ }^{\circ} \mathrm{C}$ under vacuum for $10 \mathrm{~h}$. Before the adsorption experiments, the zeolite was activated by calcination in air at $500{ }^{\circ} \mathrm{C}$ for $5 \mathrm{~h}$. In addition to the original black liquor fermentation broth (BLFB), another batch of BLFB was prepared by adding acetone, ethanol, and butanol to the original broth. This was done to arrive at two different concentrations of butanol to gain a better understanding of the competitive adsorption between different species in the fermentation broth. The composition of both broths is presented in Tables 1,2,3, and 4. The lower concentration (original broth) may be representative for in situ recovery of butanol from the fermentor while operating, whereas the broth with a higher concentration (modified broth) may be representative of a completed fermentation. Batch adsorption experiments with the original fermentation broth were performed three times to gain information on the repeatability of the method. However, due to the limited availability of fermentation broth, only one batch experiment was carried out on the modified broth. Liquid-phase batch adsorption experiments were performed in $50-\mathrm{mL}$ Erlenmeyer flasks at $\mathrm{pH} 5.2$ (original $\mathrm{pH}$ of broth) or $\mathrm{pH}$ 8. Approximately $40 \mathrm{~mL}$ fermentation broth and $1 \mathrm{~g}$ zeolite adsorbent were added to the flasks and the mixtures were allowed to equilibrate for $48 \mathrm{~h}$ at $25^{\circ} \mathrm{C}$ on a shaking table. For the experiments carried out at $\mathrm{pH} 8$, the $\mathrm{pH}$ was adjusted by addition of $1 \mathrm{M}$ sodium hydroxide solution prior to equilibration. After equilibration for $48 \mathrm{~h}$, the zeolite was separated from the solution by centrifugation. The supernatant was then filtered using a $0.2-\mu \mathrm{m}$ PTFE filter and the concentrations of adsorbates in the broth before and after equilibrium with the zeolite were determined by high-pressure liquid chromatography (HPLC, Perkin-Elmer series 200 instrument) equipped with a refractive index detector. The instrument was equipped with a 125-0115 (BioRad) column in hydrogen form and a $0.005 \mathrm{M} \mathrm{H}_{2} \mathrm{SO}_{4}$ aqueous solution in water was used as mobile phase at a flow rate of $0.6 \mathrm{~mL} / \mathrm{min}$. Additional experiments were conducted to ascertain that the filtration did not affect the composition of the supernatant.

A mass balance was used to determine the loading of the adsorbate in the zeolite:

$q_{i}=\frac{\left(C_{i, 0}-C_{i}\right) \cdot V_{o}}{m_{z, 0}}$

where $q_{i}$ is the mass of adsorbate per unit mass of adsorbent, $C_{i, 0}$ is the initial concentration of adsorbate in the solution, $C_{i}$ is the concentration of the adsorbate in the solution at equilibrium, $V_{0}$ is the volume of solution brought in contact with adsorbent, and $m_{z, 0}$ is the mass of the adsorbent.

The adsorption selectivity was calculated as follows:

$S_{\frac{i}{j}}=\frac{x_{i} / x_{j}}{y_{i} / y_{j}}$

where $x$ is the mole fraction in the adsorbed phase and $y$ is the mole fraction in the liquid phase at equilibrium.

\section{Results and discussion}

The XRD data, shown in Fig. 1, confirmed that both samples consisted of highly crystalline MFI phase. Only reflections originating from the MFI phase were observed in the diffractograms.

SEM images of the zeolite MFI powder and binderless beads are shown in Fig. 2 a, b, respectively.

For both samples, the crystal sizes vary considerably but are of roughly similar size on the order of $1 \mu \mathrm{m}$. The crystal morphologies are slightly different where the crystals making up the beads show a block-like character, whereas the crystals in the powder sample show a spherical or ellipsoidal habit. The crystals in the beads appear quite well packed with relatively small voids between the crystals. However, any difference in crystal size or morphology between the two samples

Table 1 Initial concentrations in the original black liquor fermentation broth and amount adsorbed in MFI zeolite at $\mathrm{pH} 5.2$ at $25{ }^{\circ} \mathrm{C}$; values are the average from three experiments with standard deviation indicated

\begin{tabular}{llllll}
\hline Adsorbate & $\begin{array}{l}\text { Initial concentration in } \\
\text { fermentation broth }(\mathrm{g} / \mathrm{L})\end{array}$ & $\begin{array}{l}\text { Equilibrium concentration } \\
\text { with powder }(\mathrm{g} / \mathrm{L})\end{array}$ & $\begin{array}{l}\text { Equilibrium concentration } \\
\text { with beads }(\mathrm{g} / \mathrm{L})\end{array}$ & $\begin{array}{l}\text { Amount adsorbed } \\
\text { in powder }(\mathrm{g} / \mathrm{g})\end{array}$ & $\begin{array}{l}\text { Amount adsorbed } \\
\text { in beads }(\mathrm{g} / \mathrm{g})\end{array}$ \\
\hline Acetic acid & 5.59 & 5.33 & 5.29 & $0.01 \pm 0.0001$ & $0.012 \pm 0.0005$ \\
Butyric acid & 4.35 & 2.56 & 2.60 & $0.07 \pm 0.0008$ & $0.07 \pm 0$ \\
Acetone & 0.39 & 0.38 & 0.38 & $0.0004 \pm 0$ & $0.0001 \pm 0.0003$ \\
Ethanol & 0.36 & 0.33 & 0.35 & $0.0012 \pm 0.0001$ & $0.0004 \pm 0$ \\
Butanol & 2.30 & 0.79 & 0.80 & $0.06 \pm 0.0001$ & $0.06 \pm 0.0001$ \\
\hline
\end{tabular}


Table 2 Initial concentrations in the original black liquor fermentation broth and amount adsorbed in MFI zeolite at $\mathrm{pH} 8.0$ at $25^{\circ} \mathrm{C}$; values are the average from three experiments with standard deviation indicated

\begin{tabular}{llllll}
\hline Adsorbate & $\begin{array}{l}\text { Initial concentration in } \\
\text { fermentation broth }(\mathrm{g} / \mathrm{L})\end{array}$ & $\begin{array}{l}\text { Equilibrium concentration } \\
\text { with powder }(\mathrm{g} / \mathrm{L})\end{array}$ & $\begin{array}{l}\text { Equilibrium concentration } \\
\text { with beads }(\mathrm{g} / \mathrm{L})\end{array}$ & $\begin{array}{l}\text { Amount adsorbed } \\
\text { in powder }(\mathrm{g} / \mathrm{g})\end{array}$ & $\begin{array}{l}\text { Amount adsorbed } \\
\text { in beads }(\mathrm{g} / \mathrm{g})\end{array}$ \\
\hline Acetic acid & 5.59 & 5.53 & 5.40 & $0.002 \pm 0.0001$ & $0.007 \pm 0$ \\
Butyric acid & 4.35 & 3.80 & 3.89 & $0.022 \pm 0.0005$ & $0.018 \pm 0.0002$ \\
Acetone & 0.39 & 0.19 & 0.19 & $0.008 \pm 0$ & $0.007 \pm 0.0005$ \\
Ethanol & 0.36 & 0.31 & 0.28 & $0.002 \pm 0.0001$ & $0.001 \pm 0.0001$ \\
Butanol & 2.30 & 0.11 & 0.10 & $0.086 \pm 0.0010$ & $0.088 \pm 0.0005$ \\
\hline
\end{tabular}

should not have a significant effect on the equilibrium measurements reported in this work. Figure 3 shows the nitrogen adsorption isotherms for both samples. The isotherms are quite similar, especially at lower relative pressures, and typical for microporous material with a rapid increase in the amount adsorbed at low relative pressures. At higher relative pressures, the adsorbed amounts are higher in the powder than in the beads. A hysteresis loop was observed at higher relative pressures in the isotherms of the powder sample, associated to capillary condensation in mesopores between the crystals in the powder.

The BET-specific surface areas were similar for both samples, i.e., 421 and $407 \mathrm{~m}^{2} / \mathrm{g}$ for the powder and beads, respectively. On the other hand, the mesopore volume was larger for the powder sample than for the beads as determined by the BJH method using the desorption branch, viz. 0.058 and $0.032 \mathrm{~cm}^{3} /$ $\mathrm{g}$, respectively. In our previous work, we reported breakthrough curves for model butanol/water and butanol/ethanol/acetone aqueous solutions using the same beads as in this work (particle size ca $1 \mu \mathrm{m}$ ) and compared those results with that of a structured adsorbent in the form of a ca. 9- $\mu \mathrm{m}$-thick zeolite MFI films coated on a metal monolith. For both samples, the breakthrough front was quite sharp indicating that intra-crystalline diffusion was not severely limiting the performance of the adsorbents at the conditions studied. However, the breakthrough front from the structured adsorbent was somewhat less sharp, indicating that the resistance to mass transfer was somewhat larger for this sample, as expected [34].

Table 1 shows the concentration of the main products in the ABE fermentation broth. The concentrations of acetone, butanol, and ethanol were $0.39,2.30$, and $0.36 \mathrm{~g} / \mathrm{L}$, respectively, in the original fermentation broth.

These concentrations are lower than can be expected in a complete fermentation broth where the concentrations of acetone, butanol, and ethanol are 10, 20, and $5 \mathrm{~g} / \mathrm{L}$, respectively. However, these lower concentrations may be typical for the case where it is desirable to remove butanol from the fermentor during the fermentation to prevent the inhibition of production by high concentration of butanol in the fermentor. In a previous study, we showed that even at a butanol concentration of $2 \mathrm{~g} / \mathrm{L}$, saturation loading was reached in high-silica MFI zeolite [20]. Consequently, the selectivity towards butanol in the present work should still be high. In addition, to evaluate the performance of the adsorbents also at the concentrations close to those present in an ABE broth run to completion, the original broth was spiked with additional acetone, butanol, and ethanol to arrive at the concentrations of 11.8 , 4.7 , and $19.9 \mathrm{~g} / \mathrm{L}$ respectively. The total concentration of phenolic compounds in the fermentation broth was previously determined to $0.75 \mathrm{~g} / \mathrm{L}$ [10].

Table 1 shows the batch adsorption results for both zeolite powder and for the beads from the original fermentation broth at $\mathrm{pH}$ 5.2. The results are quite similar for both the powder and beads. At this $\mathrm{pH}$, the adsorbed loading of butanol and butyric acid in the zeolite was 0.06 and $0.07 \mathrm{~g} / \mathrm{g}$ zeolite respectively. It should here be pointed out that the saturation loading of butanol or butyric acid in high-silica MFI zeolite is ca $0.12 \mathrm{~g} / \mathrm{g}$ zeolite [16, 20]. Summing up the adsorbed amounts of butanol and butyric acid yields $0.13 \mathrm{~g} / \mathrm{g}$ zeolite, i.e., almost the same as the single component saturation capacity for these two

Table 3 Initial concentration in the modified black liquor fermentation broth and amount adsorbed in MFI zeolite at pH 5.2 at $25^{\circ} \mathrm{C}$

\begin{tabular}{lccccc}
\hline Adsorbate & $\begin{array}{l}\text { Initial concentration in } \\
\text { fermentation broth }(\mathrm{g} / \mathrm{L})\end{array}$ & $\begin{array}{l}\text { Equilibrium concentration } \\
\text { with powder }(\mathrm{g} / \mathrm{L})\end{array}$ & $\begin{array}{l}\text { Equilibrium concentration } \\
\text { with beads }(\mathrm{g} / \mathrm{L})\end{array}$ & $\begin{array}{l}\text { Amount adsorbed } \\
\text { in powder }(\mathrm{g} / \mathrm{g})\end{array}$ & $\begin{array}{l}\text { Amount adsorbed } \\
\text { in beads }(\mathrm{g} / \mathrm{g})\end{array}$ \\
\hline Acetic acid & 5.59 & 5.54 & 5.55 & 0.0020 & 0.0016 \\
Butyric acid & 4.35 & 3.03 & 3.05 & 0.0528 & 0.0520 \\
Acetone & 11.80 & 11.76 & 11.77 & 0.0016 & 0.0012 \\
Ethanol & 4.70 & 4.67 & 4.68 & 0.0012 & 0.0008 \\
Butanol & 19.90 & 18.38 & 18.40 & 0.0608 & 0.0600 \\
\hline
\end{tabular}


Table 4 Initial concentration in the modified black liquor fermentation broth and amount adsorbed in MFI zeolite at pH 8.0 at $25^{\circ} \mathrm{C}$

\begin{tabular}{lccccc}
\hline Adsorbate & $\begin{array}{l}\text { Initial concentration in } \\
\text { fermentation broth }(\mathrm{g} / \mathrm{L})\end{array}$ & $\begin{array}{l}\text { Equilibrium concentration } \\
\text { with powder }(\mathrm{g} / \mathrm{L})\end{array}$ & $\begin{array}{l}\text { Equilibrium concentration } \\
\text { with beads }(\mathrm{g} / \mathrm{L})\end{array}$ & $\begin{array}{l}\text { Amount adsorbed } \\
\text { in powder }(\mathrm{g} / \mathrm{g})\end{array}$ & $\begin{array}{l}\text { Amount adsorbed } \\
\text { in beads }(\mathrm{g} / \mathrm{g})\end{array}$ \\
\hline Acetic acid & 5.59 & 5.55 & 5.56 & 0.0016 & 0.0012 \\
Butyric acid & 4.35 & 3.99 & 4.05 & 0.0144 & 0.0120 \\
Acetone & 11.80 & 11.51 & 11.53 & 0.0116 & 0.0100 \\
Ethanol & 4.70 & 4.64 & 4.66 & 0.0024 & 0.0016 \\
Butanol & 19.90 & 17.28 & 17.31 & 0.1040 & 0.1040 \\
\hline
\end{tabular}

compounds. This shows that the zeolite becomes saturated with butanol and butyric acid in this system and that the selectivity towards the $\mathrm{C} 4$ compounds is not affected by the presence of phenolic compounds in the broth. According to Kudahettige-Nilsson et al., 95\% of the substrate (in this case xylose) was utilized during the fermentation process [10]. Thus, the remaining concentration of xylose was ca. $1.4 \mathrm{~g} / \mathrm{L}$. The results obtained however shows that the unreacted substrate present in the broth seemingly did not affect the adsorption of $\mathrm{C} 4$ compounds. This is in accordance with previous reports by Ranjan et al. showing that glucose has a very low affinity for high-silica MFI [35]. Furthermore, the amount adsorbed of other components (acetic acid, acetone, and ethanol) is very low. This shows that the only component in this system, which seriously competes with butanol adsorption on high-silica MFI zeolite, is butyric acid. This may not necessarily be a problem as butyric acid has a value of its own and may also be converted into butanol, e.g., by aqueous phase hydrodeoxygenation using a heterogeneous catalyst [36, 37]. As mentioned earlier, Löwendahl et al. showed that some of the cyclic compounds present in a lignin hydrolyzate are $\mathrm{p}$ coumaric acid, ferulic acid, and syringic acid [30]. These structures may be compared to the structure of vanillin and

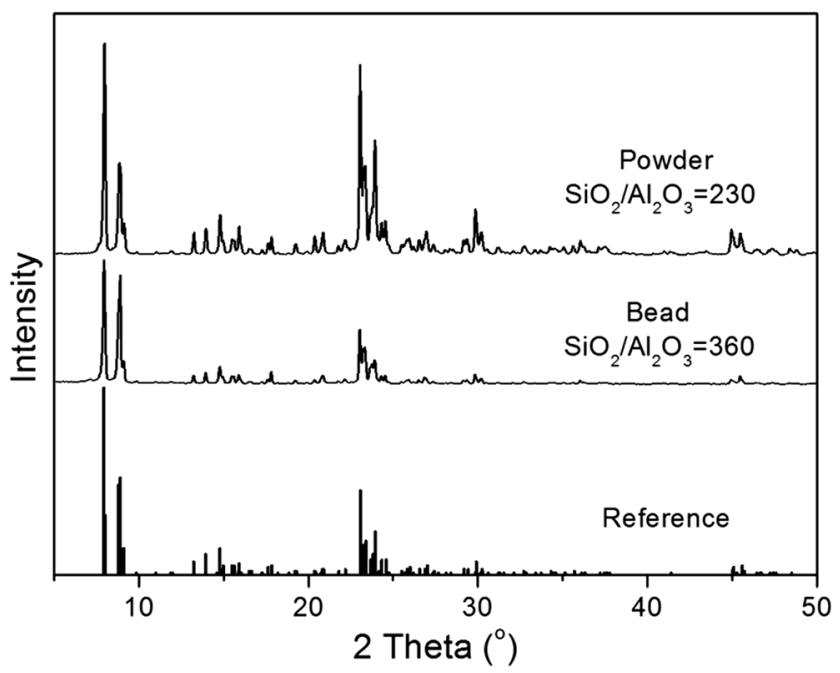

Fig. 1 X-ray diffractograms of both MFI powder and bead samples as well as a reference pattern for comparison (database reference code: 00042-0024) p-xylene [38] (see supplementary material for structures). Vanillin does not adsorb in the MFI framework even at liquid concentrations of $20 \mathrm{~g} / \mathrm{L}$, i.e., at concentrations 27 times higher than the total phenolic concentration in this work as demonstrated by Ranjan et al. [35]. The reason most likely being that the vanillin molecule is too large to enter the pores of MFI. p-Xylene has a kinetic diameter of ca. $0.58 \mathrm{~nm}$ and may enter the pore system of the MFI zeolite. Thus, pcoumaric acid, which resembles p-xylene, seems small enough to enter the pores. However, ferulic and syringic acids resemble vanillin and should not be able to enter the pores. In any case, these components do not seem to interfere with the adsorption of the $\mathrm{C} 4$ compounds; however, the reason is not clear. Perhaps, the concentration of p-coumaric acid is low enough not to interfere with adsorption of the $\mathrm{C} 4$ compounds. Further studies would be necessary to unravel this phenomenon. However, other hydrophobic adsorbents proposed for recovery of butanol from $\mathrm{ABE}$ broths but with larger effective pore diameters as compared to zeolite MFI, e.g., large pore zeolites, some metal organic frameworks and activated carbon are likely to be more affected by presence of these phenolic compounds in the broth.

We previously showed that the adsorption of butyric acid in high-silica MFI zeolite can be controlled by adjusting the $\mathrm{pH}$ of the solutions. Butyric acid is more hydrophobic than the deprotonated butyrate ion and thus shows higher affinity towards hydrophobic high-silica MFI zeolite [20]. By increasing the $\mathrm{pH}$ of the fermentation broth well above the pKa value of butyric acid (i.e., 4.82), the adsorption of butyric acid can be reduced, thus increasing the selectivity towards butanol. Table 2 shows the amount adsorbed in zeolite powder and beads from the original fermentation broth at $\mathrm{pH}$ 8.0. As expected, at this higher $\mathrm{pH}$, adsorption of butyric acid is considerably lower than that of butanol. At pH 5.2, the original $\mathrm{pH}$ of the fermentation broth, the loading of both butanol and butyric acid was approximately $0.06 \mathrm{~g} / \mathrm{g}$ zeolite, whereas at $\mathrm{pH}$ 8 , the loading of butanol was four times higher than that of butyric acid. This shows that the adsorption of butyric acid may be suppressed to increase butanol recovery and purity. The total adsorbed amount of C2 and C4 compounds is $0.11 \mathrm{~g} / \mathrm{g}$ zeolite, which indicates that the zeolite is saturated with these components and that the phenolic compounds present in the fermentation broth are not affecting the adsorption significantly. 
Fig. 2 SEM images of the crystals in the powder (a) and in the beads (b)

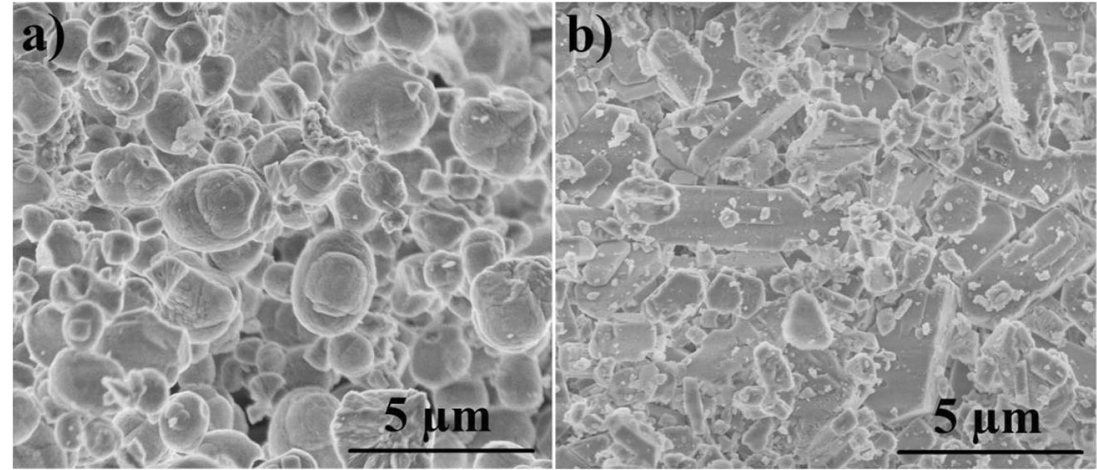

Figure 4 shows the butanol selectivity over the other components present in the original fermentation broth at $\mathrm{pH} 5.2$ and 8.0. At $\mathrm{pH} \mathrm{5.2,} \mathrm{the} \mathrm{butanol} \mathrm{over} \mathrm{butyric} \mathrm{and} \mathrm{acetic} \mathrm{acid}$ selectivities was 3 and 36, respectively. However, at $\mathrm{pH} 8.0$, the butanol selectivity increases significantly as the high-silica MFI zeolite shows less affinity towards the deprotonated carboxylic acids; consequently, the butanol selectivities increased to 190 and 678, over butyric and acetic acid, respectively. However, as the adsorption of the acids is decreased at high $\mathrm{pH}$, the adsorption of acetone increases, whereas adsorption of ethanol decreases. This is expected as acetone shows higher affinity towards high-silica MFI than ethanol [16, 18, 20].

Tables 3 and 4 show the batch adsorption experiment results from modified black liquor fermentation broth at $\mathrm{pH} 5.2$ and 8 , respectively. The results are in general very similar to those obtained for the original fermentation broth. At $\mathrm{pH}$ 5.2, primarily a mixture of butanol and butyric acid is adsorbed, whereas at $\mathrm{pH} 8$, adsorption of butyric acid is reduced and the adsorbed phase mostly consists of butanol. At both $\mathrm{pH}$ values, the sum of the amount adsorbed of butanol and butyric acid is very close to the saturation loading of high-silica MFI zeolite,

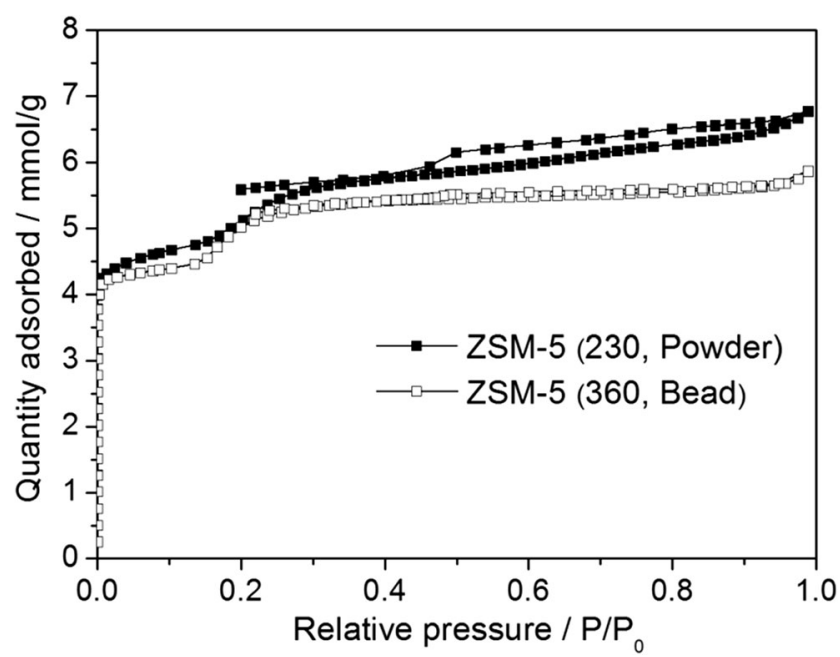

Fig. 3 Nitrogen adsorption/desorption isotherms for both samples determined at $77 \mathrm{~K}$ hence showing again that phenolic compounds are not affecting the adsorption of $\mathrm{C} 4$ compounds.

Figure 5 shows the same trend as in Fig. 4; at low pH, the butanol selectivities over acetic and butyric acid were determined to 36 and 0.2 , respectively. The low selectivity over butyric acid in this case is due to the fact that even though the concentration of butanol was quite high as compared to butyric acid in the modified fermentation broth, still, butyric acid competes with the butanol for adsorption sites (see Table 3). However, at $\mathrm{pH} 8.0$, butanol selectivity over butyric acid increases slightly, as expected.

The lower selectivity values observed for the modified broth at $\mathrm{pH} 8$ compared to the corresponding values for the original broth may be explained with that the adsorption of butanol is close to saturation (ca $0.11 \mathrm{~g} / \mathrm{g}$ ) already at the low concentrations found in the original broth. Thus, for the modified solution with higher concentration of butanol in solution, the adsorbed amount will not change to any great extent compared to adsorption from the original broth as the adsorbent is already close to saturation. Instead, the determined selectivity will be reduced as the denominator in Eq. 2 now takes a greater value which results in lower observed selectivities. Several groups have previously reported butanol loading in adsorbents from model solutions and real fermentation broth $[6,15,16,19]$, but to the best of our knowledge, none of these studies reported any selectivity data. However, Cousin Saint Remi et al. reported butanol over ethanol and acetone selectivities of 10.2 and 2.6, respectively, for a ZIF-8 metal organic framework using a model fermentation broth and data from breakthrough [17]. In our previous study, we reported butanol over ethanol and butanol over acetone selectivities of 7.3 and 4.4, respectively, for silicalite-1 beads and breakthrough experiments using model fermentation broths [20]. The differences compared to the results obtained in this work can be ascribed to the different composition of the broth used, mode of measurement, i.e., batch vs breakthrough experiments, and of course the different material used when it comes to comparing with the ZIF-8 material. As pointed 
Fig. 4 Butanol selectivity over other components present in original black liquor fermentation broth at $\mathrm{pH} 5.2$ (empty bars) and $\mathrm{pH} 8.0$ (filled bars) at $25^{\circ} \mathrm{C}$

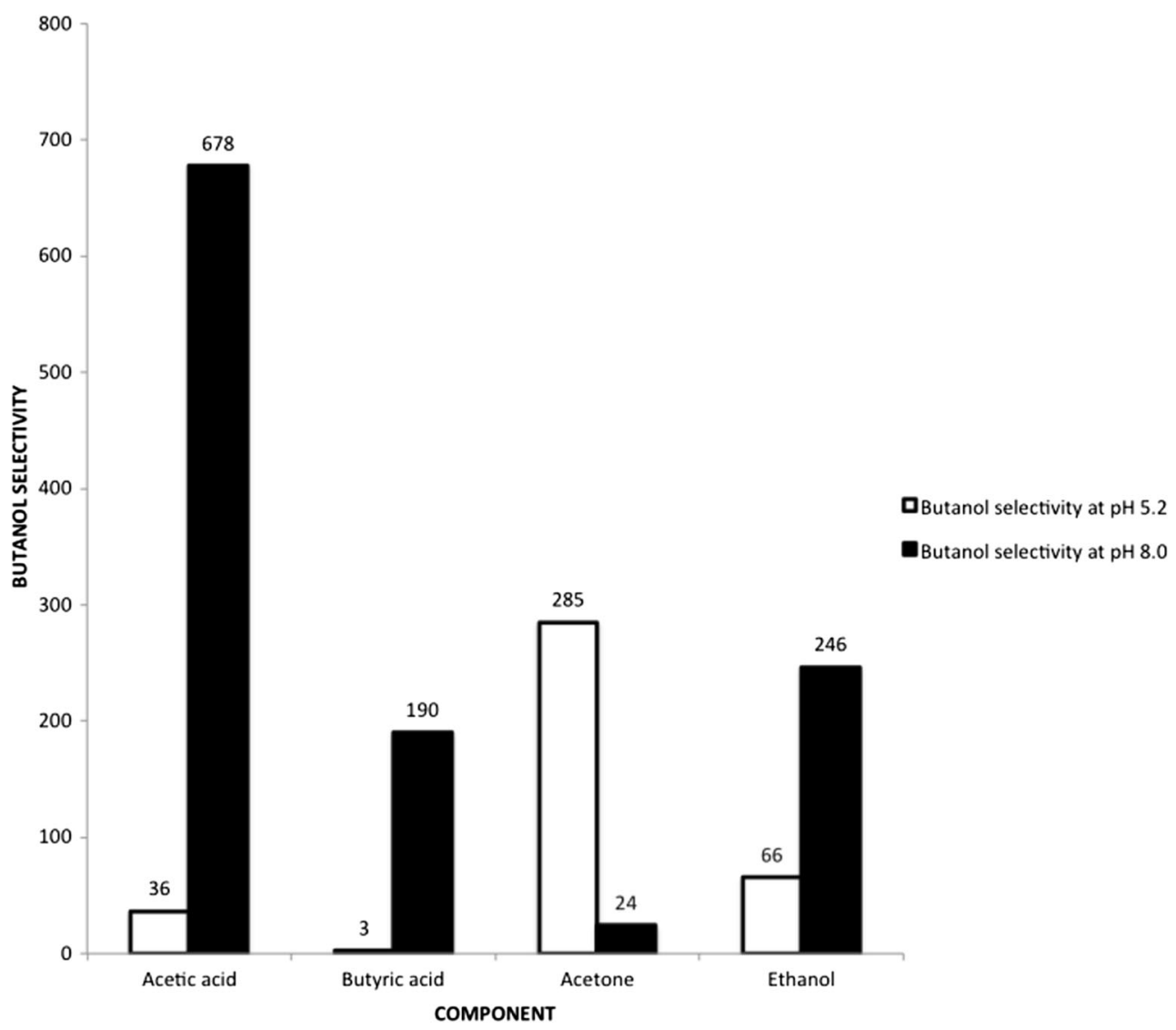

out above, this is the first study in which black liquorderived fermentation broth was used; hence, no data is available in the literature to compare these selectivity values for this particular broth containing relatively high concentrations of phenolic compounds. In addition, to the best of our knowledge, this is the first report presenting results on butanol selectivities over butyric and acetic acid for an ABE fermentation broth.
Fig. 5 Butanol selectivity over other components present in modified black liquor fermentation broth at $\mathrm{pH} 5.2$ (empty bars) and $\mathrm{pH} 8.0$ (filled bars) at $25^{\circ} \mathrm{C}$

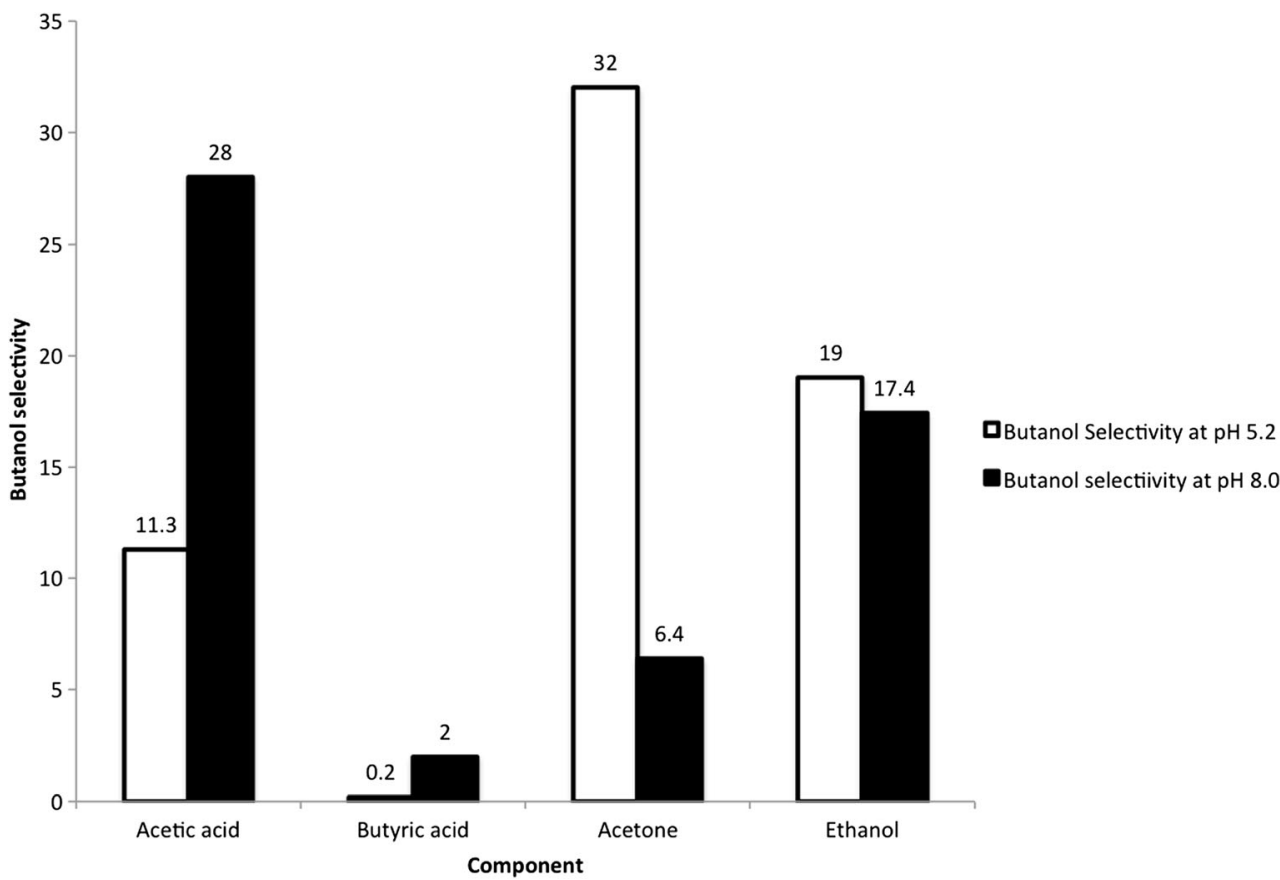


In this work, we chose to keep the temperature constant but changing the temperature would affect both the adsorption selectivities and the uptake rate. The uptake rate is increasing with increasing temperature, whereas the adsorption selectivity will decrease if the temperature is raised sufficiently, so there is an optimum temperature where the mass transfer is as high as possible while still maintaining a high butanol selectivity. To assure a high butanol concentration in the adsorbent, and thereby in the final product, it is imperative that the concentration of butanol in the adsorbent is close to the saturation concentration; if the temperature is increased too much, this would not be the case. Consequently, to ascertain a high concentration of butanol in the product, there is a maximum temperature above which the butanol selectivity will decrease rapidly; this temperature is of course dependent on the composition of the broth. For example, at the butanol concentrations found in the original broth, increasing the temperature may not be a feasible option, as it would likely compromise the adsorption selectivity as the adsorbed concentration of butanol is close to the concentration in solution where saturation loading is achieved [20]. However, for the composition used in the modified broth with a butanol concentration that is ca. 9 times higher (i.e., ca. $20 \mathrm{~g} / \mathrm{L}$ ), it would likely be possible to increase the temperature somewhat without compromising the adsorption selectivity as at this high concentration of butanol in solution, the adsorbed loadings are far from the point where the adsorbed loadings start decreasing (high up in the flat part of the isotherm). Therefore, when optimizing the temperature, both the effect on the adsorption selectivity and on the uptake rate should be taken into account, e.g., by performing breakthrough experiments at different temperatures, such an optimization is however beyond the scope of the present work.

Recent research shows that the butanol/water adsorption selectivity of a MFI adsorbent may be further increased by decreasing the density of structural defects, in the form of silanol groups, present in the framework $[25,26]$. These defects are formed during conventional zeolite synthesis at high $\mathrm{pH}$. The density of structural defects was decreased by synthesizing the zeolite at neutral $\mathrm{pH}$ using fluoride ions as mineralizing agent. With a reduced concentration of structural defects, much less water adsorbs in the zeolite which results in an increase in the adsorption selectivity $[26,39,40]$. In future work, it would be interesting to evaluate also these materials as adsorbents in real fermentation broths. Nevertheless, in the present work, we demonstrate that high-silica MFI zeolite shows high adsorption selectivity for butanol against the other main compounds present in real fermentation broths and that the adsorbent is seemingly insensitive to the presence of phenolic compounds in the fermentation broth. However, more studies are needed to confirm or reject any minor adsorption of phenolic acids on high silica MFI zeolite. In addition, future studies should focus on measuring dynamic parameters like uptake rate, flow rate, etc. using breakthrough experiments to further assess the feasibility of implementing this process in biorefineries.

\section{Conclusions}

In this study, high-silica MFI zeolite was used as adsorbent to recover butanol from $\mathrm{ABE}$ fermentation broths derived from a black liquor hydrolyzate, a potential source for inexpensive substrate. The hydrolyzate contained significant amounts of phenolic compounds that potentially could affect the adsorption of the desired $\mathrm{C} 4$ products. It was shown that despite the presence of the phenolic compounds in the fermentation broths, the high-silica MFI zeolite adsorbent was very selective towards the $\mathrm{C} 4$ products viz. butanol and butyric acid. In addition, by increasing the $\mathrm{pH}$ of the fermentation broth, coadsorption of butyric acid could be suppressed, further increasing butanol selectivity. The selectivity of butanol over acetic acid, butyric acid, acetone, and ethanol was reported at $\mathrm{pH} 5.2$ and $\mathrm{pH} 8.0$ for two broths with different compositions. High-silica MFI zeolite showed higher affinity towards butanol than any other compound present in the fermentation broth. The results presented herein are promising for better utilization of the black liquor stream. However, further studies on the performance under dynamic conditions with, e.g., breakthrough experiments, should be conducted.

Acknowledgements Special thanks go to biochemical research group at Luleå University of Technology for providing the fermentation broth. Dr. Faiz Ullah Shah is also acknowledged for helpful discussions.

Funding information The authors wish to thank Formas, the Swedish Energy Agency, VINNOVA, Smurfit Kappa, and Bio4Energy, a strategic research environment appointed by the Swedish government, for financially supporting this work.

Open Access This article is distributed under the terms of the Creative Commons Attribution 4.0 International License (http:// creativecommons.org/licenses/by/4.0/), which permits unrestricted use, distribution, and reproduction in any medium, provided you give appropriate credit to the original author(s) and the source, provide a link to the Creative Commons license, and indicate if changes were made.

Publisher's Note Springer Nature remains neutral with regard to jurisdictional claims in published maps and institutional affiliations.

\section{References}

1. Kevlich N, Shofner M, Nair S (2017) Membranes for Kraft black liquor concentration and recovery: current progress, challenges and opportunities. Sep Sci Technol 52(6):1070-1094

2. Helmerius J, von Walter JV, Rova U, Berglund KA, Hodge DB (2010) Impact of hemicellulose pre-extraction for bioconversion on birch Kraft pulp properties. Bioresour Technol 101(15):59966005

3. Toledano A, Serrano L, Garcia A, Mondragon I, Labidi J (2010) Comparative study of lignin fractionation by ultrafiltration and selective precipitation. Chem Eng J 157(1):93-99

4. Pettersson K, Harvey S, Berntsson T (2012) Comparison of options for debottlenecking the recovery boiler at Kraft pulp mills-economic performance and CO2 emissions. ECOS, Perugia, pp 1-17 
5. Friedl A, Qureshi N, Maddox IS (1991) Continuous acetonebutanol-ethanol (ABE) fermentation using immobilized cells of Clostridium acetobutylicum in a packed bed reactor and integration with product removal by pervaporation. Biotechnol Bioeng 38(5): 518-527

6. Abdehagh N, Tezel FH, Thibault J (2014) Separation techniques in butanol production: challenges and developments. Biomass Bioenergy 60:222-246

7. Bankar SB, Survase SA, Ojamo H, Granström T (2013) Biobutanol: the outlook of an academic and industrialist. RSC Adv 3(47):24734-24757

8. Ezeji T, Qureshi N, Blaschek H (2004) Acetone butanol ethanol (ABE) production from concentrated substrate: reduction in substrate inhibition by fed-batch technique and product inhibition by gas stripping. Appl Microbiol Biotechnol 63(6):653-658

9. Maddox I, Steiner E, Hirsch S, Wessner S, Gutierrez N, Gapes J, Schuster K (2000) The cause of "Acid Crash" and "Acidogenic Fermentations" during the batch acetone-butanol-ethanol(ABE-) fermentation process. J Mol Microbiol Biotechnol 2(1):95-100

10. Kudahettige-Nilsson RL, Helmerius J, Nilsson RT, Sjöblom M, Hodge DB, Rova U (2015) Biobutanol production by Clostridium acetobutylicum using xylose recovered from birch Kraft black liquor. Bioresour Technol 176:71-79

11. Mesfun S, Lundgren J, Grip C, Toffolo A, Nilsson RLK, Rova U (2014) Black liquor fractionation for biofuels production-a technoeconomic assessment. Bioresour Technol 66:508-517

12. Thirmal C, Dahman Y (2012) Comparisons of existing pretreatment, saccharification, and fermentation processes for butanol production from agricultural residues. Can J Chem Eng 90(3):745-761

13. Qureshi N, Hughes S, Maddox I, Cotta M (2005) Energy-efficient recovery of butanol from model solutions and fermentation broth by adsorption. Bioprocess Biosyst Eng 27(4):215-222

14. Oudshoorn A, van der Wielen, Luuk AM, Straathof AJ (2009b) Assessment of options for selective 1-butanol recovery from aqueous solution. Ind Eng Chem Res 48(15):7325-7336

15. Abdehagh N, Gurnani P, Tezel FH, Thibault J (2015) Adsorptive separation and recovery of biobutanol from $\mathrm{ABE}$ model solutions. Adsorption 21(3): 185-194

16. Oudshoorn A, van der Wielen, Luuk AM, Straathof AJ (2009a) Adsorption equilibria of bio-based butanol solutions using zeolite. Biochem Eng J 48(1):99-103

17. Saint Remi JC, Baron G, Denayer J (2012) Adsorptive separations for the recovery and purification of biobutanol. Adsorption 18(56):367-373

18. Saravanan V, Waijers D, Ziari M, Noordermeer M (2010) Recovery of 1-butanol from aqueous solutions using zeolite ZSM-5 with a high $\mathrm{Si} / \mathrm{Al}$ ratio; suitability of a column process for industrial applications. Biochem Eng J 49(1):33-39

19. Águeda VI, Delgado JA, Uguina MA, Sotelo JL, García Á (2013) Column dynamics of an adsorption-drying-desorption process for butanol recovery from aqueous solutions with silicalite pellets. Sep Purif Technol 104:307-321

20. Faisal A, Zarebska A, Saremi P, Korelskiy D, Ohlin L, Rova U, Hedlund J, Grahn M (2014) MFI zeolite as adsorbent for selective recovery of hydrocarbons from $\mathrm{ABE}$ fermentation broths. Adsorption 20(2-3):465-470

21. DeJaco R, Bai P, Tsapatsis M, Siepmann I (2016) Adsorptive separation of 1-butanol from aqueous solutions using MFI- and FERtype zeolite frameworks: a Monte Carlo study. Langmuir 32:20932101

22. van der Perre S, Gelin P, Claessens B et al (2017) Intensified biobutanol recovery by using zeolites with complementary selectivities. ChemSusChem 10(14):2968-2977
23. Lin X, Li R, Wen Q, Wu J, Fan J, Jin X, Qian W, Liu D, Chen X, Chen Y (2013) Experimental and modeling studies on the sorption breakthrough behaviors of butanol from aqueous solution in a fixed-bed of KA-I resin. Biotechnol Bioprocess Eng 18(2):223-233

24. Nielsen DR, Prather KJ (2009) In situ product recovery of n-butanol using polymeric resins. Biotechnol Bioeng 102(3):811-821

25. Farzaneh A, Zhou M, Potapova E, Bacsik Z, Ohlin L, Holmgren A, Hedlund J, Grahn M (2015) Adsorption of water and butanol in silicalite-1 film studied with in situ attenuated total reflectanceFourier transform infrared spectroscopy. Langmuir 31(17):48874894

26. Farzaneh A, Zhou M, Antzutkin ON, Bacsik Z, Hedlund J, Holmgren A, Grahn M (2016) Adsorption of butanol and water vapors in silicalite-1 films with a low defect density. Langmuir 32(45):11789-11798

27. Faustino H, Gil N, Baptista C, Duarte AP (2010) Antioxidant activity of lignin phenolic compounds extracted from Kraft and sulphite black liquors. Molecules 15(12):9308-9322

28. Hattalli S, Benaboura A, Ham-Pichavant F, Nourmamode A, Castellan A (2002) Adding value to Alfa grass (Stipa tenacissima L.) soda lignin as phenolic resins 1 . Lignin characterization. Polym Degrad Stab 76(2):259-264

29. Löwendahl L, Petersson G, Samuelson O (1978) Phenolic compounds in Kraft black liquor. Sven Pap 81(12):392-396

30. Hameed B, Rahman A (2008) Removal of phenol from aqueous solutions by adsorption onto activated carbon prepared from biomass material. J Hazard Mater 160(2):576-581

31. Gundogdu A, Duran C, Senturk HB, Soylak M, Ozdes D, Serencam H, Imamoglu M (2012) Adsorption of phenol from aqueous solution on a low-cost activated carbon produced from tea industry waste: equilibrium, kinetic, and thermodynamic study. J Chem Eng Data 57(10):2733-2743

32. Dąbrowski A, Podkościelny P, Hubicki Z, Barczak M (2005) Adsorption of phenolic compounds by activated carbon - a critical review. Chemosphere 58(8):1049-1070

33. Oudshoorn A, Van der Wielen L, Straathof A (2012) Desorption of butanol from zeolite material. Biochem Eng J 67:167-172

34. Faisal A, Zhou M, Hedlund J, Grahn M (2016) Recovery of butanol from model ABE fermentation broths using MFI adsorbent: a comparison between traditional beads and a structured adsorbent in the form of a film. Adsorption 22(2):205-214

35. Ranjan R, Thust S, Gounaris CE, Woo M, Floudas CA, von Keitz M, Valentas KJ, Wei J, Tsapatsis M (2009) Adsorption of fermentation inhibitors from lignocellulosic biomass hydrolyzates for improved ethanol yield and value-added product recovery. Microporous Mesoporous Mater 122(1):143-148

36. Chen L, Zhu Y, Zheng H, Zhang C, Zhang B, Li Y (2011) Aqueousphase hydrodeoxygenation of carboxylic acids to alcohols or alkanes over supported Ru catalysts. J Mol Catal A Chem 351:217227

37. Lee J, Upare PP, Chang J, Hwang YK, Lee JH, Hwang DW, Hong D, Lee SH, Jeong M, Kim YD (2014) Direct hydrogenation of biomass-derived butyric acid to n-butanol over a ruthenium-tin bimetallic catalyst. ChemSusChem 7(11):2998-3001

38. Hedlund J, Öhrman O, Msimang V, van Steen E, Böhringer W, Sibya S, Möller K (2004) The synthesis and testing of thin film ZSM-5 catalysts. Chem Eng Sci 59(13):2647-2657

39. Zhang K, Lively RP, Noel JD, Dose ME, McCool BA, Chance RR, Koros WJ (2012) Adsorption of water and ethanol in MFI-type zeolites. Langmuir 28(23):8664-8673

40. Farzaneh A, DeJaco R, Ohlin L, Holmgren A, Siepmann I, Grahn M (2017) Comparative study of the effect of defects on the selective adsorption of butanol from butanol/water binary vapor mixtures in silicalite-1 films. Langmuir 33:8420-8427 